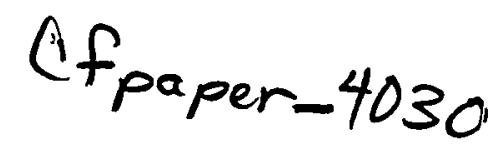

\title{
The Development of RF Heating of Magnetically Confined Deuterium-Tritium Plasmas
}

\author{
J. C. Hosea, S. Bernabei, B. P. LeBlanc, R. Majeski, C. K. Phillips, G. \\ Schilling, J. R. Wilson, and the TFTR Team \\ Princeton Plasma Physics Laboratory, Princeton, N. J. 08543
}

\begin{abstract}
The experimental and theoretical development of ion cyclotron radiofrequency heating (ICRF) in toroidal magnetically-confined plasmas recently culminated with the demonstration of ICRF heating of D-T plasmas, first in the Tokamak Fusion Test Reactor (TFTR) and then in the Joint European Torus (JET). Various heating schemes based on the cyclotron resonances between the plasma ions and the applied ICRF waves have been used, including second harmonic tritium, minority deuterium, minority helium-3, mode conversion at the D-T ion-ion hybrid layer, and and ion Bernstein wave heating. Second harmonic tritium heating was first shown to be effective in a reactor-grade plasma in TFTR. D-minority heating on JET has led to the achievement of $Q=0.22$, the ratio of fusion power produced to RF power input, sustained over a few energy confinement times. In this paper, some of the key building blocks in the development of $\mathrm{rf}$ heating of plasmas are reviewed and prospects for the development of advanced methods of plasma control based on the application of rf waves are discussed.
\end{abstract}

\section{INTRODUCTION}

The quest for providing if heating schemes to heat magnetically confined, toroidal D-T plasmas for reactor relevant parameters began three decades ago. Significant progress has been made over this time by combining incremental steps in both experiments and theory. It is important to note that at times theoretical understanding followed experimental discovery and at other times experimental verification followed theoretical prediction. Ultimately, a significant number of ICRF heating regimes - most notably second harmonic tritium with and without ${ }^{3} \mathrm{He}$, minority deuterium, and ion-ion hybrid mode conversion - have been explored and validated in deuterium plasmas and recently demonstrated to be viable in the D-T regime on TFTR and JET.

\section{WAVE COUPLING, PROPAGATION AND ABSORPTION OVER THE CROSS-SECTION OF THE TOROIDAL PLASMA}

Early experiments on the ST tokamak established coupling and heating at $2 \Omega_{\mathrm{D}}(1)$. The rf waves that were launched from the inboard side of the plasma (smaller major $R$ ) with half-turn rf current elements, propagated radially and toroidally and were absorbed at ion resonances in the plasma. The most efficient heating was obtained with the $2 \Omega_{D}$ ion resonance located near the center of the plasma column. This result was not understood at the time since the damping of the waves was much stronger than predicted by second harmonic theory. Subsequently, it was shown theoretically that the strong wave damping could be explained by minority hydrogen fundamental ion cyclotron damping of the fast wave (2). A small concentration of hydrogen in the plasma was sufficient to give mode coupling to the ion Bernstein wave, causing an enhancement of 


\section{DISCLAIMER}

This report was prepared as an account of work sponsored by an agency of the United States Government. Neither the United States Government nor any agency thereof, nor any of their employees, make any warranty, express or implied, or assumes any legal liability or responsibility for the accuracy, completeness, or usefulness of any information, apparatus, product, or process disclosed, or represents that its use would not infringe privately owned rights. Reference herein to any specific commercial product, process, or service by trade name, trademark, manufacturer, or otherwise does not necessarily constitute or imply its endorsement, recommendation, or favoring by the United States Government or any agency thereof. The views and opinions of authors expressed herein do not necessarily state or reflect those of the United States Government or any agency thereof. 


\section{DISCLAIMER}

Portions of this document may be illegible in electronic image products. Images are produced from the best available original document. 
left hand polarization and cyclotron damping into the hydrogen species which in turn heated the majority deuterium ions and electrons.

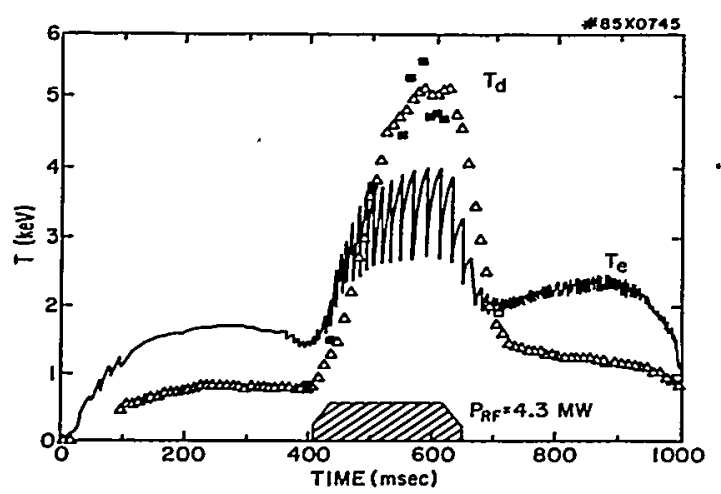

FIGURE 1. ${ }^{3} \mathrm{He}$ minority ion heating regime on PLT (Ref.4) $-n_{e}=3.7 \times 10^{13} \mathrm{~cm}^{-3}, B_{\phi}=3.25$ Tesla.

Experiments on a large number of tokamaks verified the elements of the mode coupling theory. This combined with coupler development for high power density wave launching set the stage for demonstrating the feasibility of using this minority ion heating scheme in the toroidal reactor regime. Following the successful development of high power if feedthroughs (3), heating to reactor relevant temperatures was first demonstrated on the PLT tokamak as shown in Fig. 1 (4).

Direct second harmonic heating of deuterium was observed on PLT after the hydrogen concentration had been reduced sufficiently (4). However, a clear indication of what could be expected for second harmonic heating in the absence of a minority ion species was obtained for $2 \Omega_{\mathrm{H}}$ operation on PLT as shown in Fig. 2 (5).

At elevated minority ion density, mode coupling transforms into mode conversion into the ion Bernstein wave which provides a method for depositing launched fast wave energy in a very localized radial region of the plasma cross-section via ion Bernstein
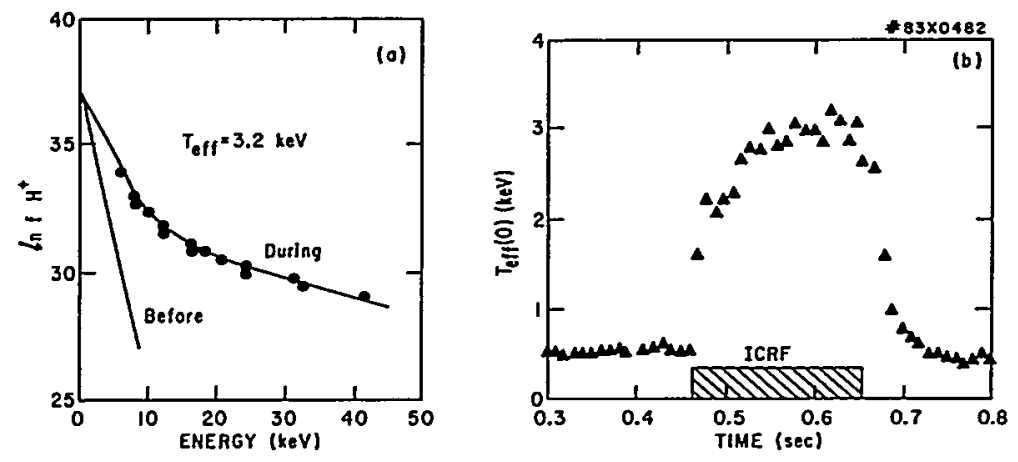

FIGURE 2. Second harmonic hydrogen heating regime on PLT (Ref. 5).

wave damping (6). When the ion temperature is not too high, local electron heating is favored. Such mode conversion experiments in $\mathrm{D}-{ }^{3} \mathrm{He}$ plasmas produced the highest electron heating efficiency of any heating method used on the TFTR tokamak (7).

\section{INTERACTION OF RF WAVES WITH FAST PARTICLES}

A by-product of minority ion and second harmonic heating is the production of very energetic ion energy distributions which are in quantitative agreement with the prediction of theory (8). The first evidence that the energetic ion beta could be affecting core plasma stability was the observation of giant sawteeth on PLT (e.g., see Fig. 1). If the energetic ion beta is sufficiently high, the sawtooth instability is stabilized completely as first shown on the JET tokamak (9) and then on TFTR (10). However, the rf produced energetic ions can produce Alfven instabilities as predicted theoretically (11) and then first measured on TFTR (12). These instabilities in turn can interact with the energetic ions, transporting them out of the core and possibly into ripple trapping regions of the 
plasma and resulting in significant ion loss from the plasma (13). Further study has shown that high energetic ion beta in the plasma core is responsible for exciting core Alfven waves (energetic particle modes) which in turn push the energetic ions out of the core and end the sawtooth stability period (14). The loss of energetic particles from the core of the reactor plasma could affect the sawtooth stability but the spacial redistribution of ions should not result in significant ion losses since the ripple trapping zones will be removed from the interior of the plasma.

The effective temperature of the energetic ion distribution is reduced as the plasma density is increased and thus Alfven instabilities may play a less important role at high operating densities. Also, the high energy ion component is reduced for second harmonic heating relative to that for fundamental minority heating and Alfven instability effects should be reduced. For both fundamental and second harmonic heating the instability effects can now be predicted quantitatively and evaluated for the reactor regimes of interest. For the ion-ion mode conversion regime the rf wave damping is into the bulk of either the electron or ion distributions and both sawtooth stabilization and Alfven instability effects should be absent.

\section{ICRF EXPERIMENTS PERFORMED IN D-T PLASMAS}

A detailed overview of the heating results obtained on TFTR and JET is given at this conference by C. K. Phillips (15). Here, the focus is on demonstrating the applicability of the heating methods proven earlier to reactor plasma conditions. First, the heating results for second harmonic tritium, with and without an admixture of minority ${ }^{3} \mathrm{He}$ ions, demonstrate that this is the most suitable if method for heating a reactor plasma from a cold start to ignition. On TFTR second harmonic heating of an ohmically heated D-T target plasma was shown to be equivalent to neutral beam heating at the same power (16) [see Fig. 3], and efficient second harmonic heating of a very high temperature neutral beam heated D-T target plasma was also shown (17). Furthermore, ${ }^{3} \mathrm{He}$ minority heating was shown to enhance the heating efficiency for both electrons and ions.

The heating of a DT plasma using

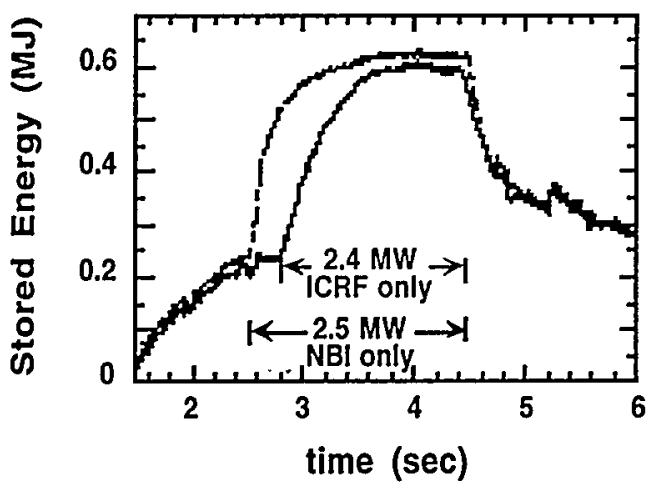

FIGURE 3. Heating in the $2 \Omega_{\mathrm{T}}$ regime on TFTR (Ref. 16). the minority ion if heating scheme was employed successfully on JET (18). As for the earlier heating cases with $\mathrm{H}$ and ${ }^{3} \mathrm{He}$ ions, a very energetic D ion energy distribution was produced for $\mathrm{D}$ minority concentrations up to $\sim 20 \%$. This nonMaxwellian ion distribution enhanced the neutron production and resulted in a record 1.7 MW of fusion power with an applied rf power of $\sim 6 \mathrm{MW}(\mathrm{Q} \sim$ 0.22 ). At higher concentrations of $D$, the mode conversion regime was entered and the fusion power production was reduced as expected.

Mode conversion heating in the D-T regime was studied extensively on TFTR $(16,19,20)$. First, it was shown that ${ }^{7} \mathrm{Li}$ had to be replaced by ${ }^{6} \mathrm{Li}$ to avoid strong minority lithium absorption between the ion-ion hybrid and deuterium fundamental resonance layers. Then strong, localized mode conversion heating of the tritium ions was demonstrated in the hot ion core $\left(T_{i} \sim 20-30 \mathrm{keV}\right)$ of a neutral beam heated target plasma. 


\section{SUMMARY}

Second harmonic heating at the $2 \Omega_{\mathrm{T}}\left(\Omega_{\text {helium }}{ }_{3}\right)$ ion cyclotron resonance has been shown to be a viable technique for heating a reactor plasma. Optimization of the heating efficiency as well as minimization of the tritium fuel required to reach ignition can be achieved by balancing the heating between the second harmonic $\mathrm{T}$ and minority ${ }^{3} \mathrm{He}$ regimes during the reactor startup. Fundamental $D$ minority heating is also viable for the startup of the reactor plasma but will require considerably more $T$ than the second harmonic case. Also, optimization of fusion power production may be difficult while maintaining a relatively low minority $\mathrm{D}$ concentration to avoid mode conversion. Following the minority regime with the mode conversion regime is probably preferable for achieving steady state burn conditions. However, the results from TFTR demonstrate that concentrations of the light metals $(\mathrm{Li}, \mathrm{Be}, \mathrm{B})$ will have to be controlled to very low concentrations to prevent minority damping into them from dominating D-T mode conversion heating.

For the heating regimes discussed in this paper, there is very good agreement between rf heating experiments and theory with regard to wave physics, particle physics, and Alfven instability effects. Thus, the physics embodied in these toroidal regimes is generally applicable to magnetic topologies of interest for magnetic fusion concepts.

\section{AKNOWLEDGEMENTS}

This work was supported by the U.S. Department of Energy under Contract No. AC02-76-CH0-3073

\section{REFERENCES}

1. Adam,J., et al., "Plas. Phys. and Contr. Fus. Res.", IAEA I (1975) 65.

2. Stix, T., Nuclear Fusion 15 (1975) 737.

3. Hwang,D., Grotz, G., and Hosea, J., J. Vac. Sci. Technol. 20 (1982) 1273.

4. Wilson, J., et al., RF Heating Conf., AIP 129 (1985) 28; Hosea, J., et al., EPS II (1985) 120.

5. Hwang, D., et al., Phys. Rev. Letts. 51 (1983) 1865.

6. Majeski, R., Phillips, C., and Wilson, J., Phys. Rev. Letts. 73 (1994) 2204.

7. Majeski, R., et al., Phys. Rev. Letts. 76 (1996) 754.

8. Hosea, J. et al., Phys. Rev. Letts. 43 (1979) 1802.

9. Jacquinot, J., et al., "Plas. Phys. and Contr. Fus. Res.", IAEA I (1987) 449.

10. Kieras-Phillips, C., et al., Phys. Fluids B4 (1992) 2155.

11. Biglari, H., Zonca, F., and Chen, L., Phys. Fluids B 4 (1992) 2385.

12. Wilson, J., et al., "Plas. Phys. and Contr. Fus. Res.", IAEA I (1993) 661.

13. Bernabei, S., et al., Phys. of Plasmas 6 (1999) 1880.

14. Bernabei, S., et al., This AIP RF Heating Conf.

15. Phillips, C., et al., This AIP RF Heating Conf.

16. Rogers, J., et al., "Plas. Phys. and Contr. Fus. Res.", IAEA III (1997) 317.

17. Taylor, G., et al., "Plas. Phys. and Contr. Fus. Res.", IAEA I (1995) 431.

18. Start, D., et al., "Plas. Phys. and Contr. Fus. Res.", IAEA (1999) paper F1-CN-69/CD1/2.

19. Wilson, J., et al., Phys. of Plasmas 5 (1998) 1721.

20. Phillips, C., et al., "Plas. Phys. and Contr. Fus. Res.", IAEA (1999) paper F1-CN-69/CDP/09. 